\title{
Indonesian Seastate Condition and Its Wave Scatter Map
}

\author{
Fredhi Agung Prasetyo a,*, Mohammad Arif Kurniawan ${ }^{\mathrm{b}}$ and Siti Komariyah $^{\mathrm{c}}$ \\ Research and Development Division, Biro Klasifikasi Indonesia, Jakarta, Indonesia \\ a.fredhiagung@bki.co.id,b.arif.kurniawan@bki.co.id,c.siti.komariyah@bki.co.id \\ *corresponding author
}

Keywords: Indonesian waterways, sea-state, long-term distribution, weibull distribution, wave scatter.

\begin{abstract}
Global Wave statistics (GWS) that is commonly used as references for the ocean environmental source requires wave scatter diagram as data sources. Within GWS, 104 areas in the world are covered, and each area has its wave scatter data. The wave scatter data could present the properties of significant wave height at the corresponding area, such as the maximum sea state condition, long-term probability, mean cross period, and wave spectrum specification. Generally, GWS covers the ocean around the world, however, there are some areas that are cover on the map. The example of uncovered area is Indonesian waterways. In order to give additional information of ocean environmental condition for the blank spot area, it is needed to develop the Indonesian wave scatter map/diagram. In this report, the Indonesian wave scatter map/diagram is developed based on the hind cast data that is collected from spatial area covered from $75^{\circ} \mathrm{E}$ to $165^{\circ} \mathrm{E}$ and $15^{\circ} \mathrm{N}$ to $15^{\circ} \mathrm{S}$. The European Center for Medium range weather forecasts (ECMWF) are chosen to provide the source data of significant wave height, mean period and wave direction. The time history of significant wave height, mean period and wave direction are compiled, assembled and analyzed to provide the advanced information of Indonesian waterways characteristics. The statistical characteristics of the data is also examined and discussed.
\end{abstract}

\section{Introduction}

In the term of ship design and/ or offshore floating structure, the enviromental data is one of the important thing that should be identified in the beginning of the process. Since it will be used also in the assessment stage of ship design and/or offshore floating structure.In the ship design or in term of classificaton society (CS) requirements, these assessments stage will fullfill the following limit state [1], such as serviceable limit state (SLS), Ultimate limit state (ULS), fatigue limit state (FLS) and accidental limit state (ALS). Mostly all limit states require the enviromental data by considering an operation location of unrestricted navigations. [1] and [2] are based on the basis data of enviromental conditions on the North Atlantic Oceans. In common practise, the North Atlantic Ocean wave enviromental is chosen from the data presented by Global wave statistics (GWS) [3] or standard wave data [4].

The wave enviromental location as mentioned above may become a question if the specific vessel operation is only in the calm waters other than that of North Atlantics Ocean, ie. Java sea, or in general 
Indonesian waterways. This condition become the disadvantage to the ship designer, since the ship's structure or offshore floating structure calculation might be overestimated. The wave data of Indonesian waterways is needed. However, Indonesia waterways is not supported by the GWS map [3].

In this report, the final proposal to support Indonesian wave enviroment data is proposed based on the hindcast data. This report is also compiling the previous work that already reported. The characteristics of supported wave data will be discussed.

\section{The Indonesian Waterways}

\subsection{Indonesian Waterways}

It is explained briefly in the Introduction that Indonesian area is not supported by GWS map. Lets figure the area of GWS as shown in Figure 1. The total 104 areas of worldwide ocean are covered up. This area include the North Atlantic Ocean, which are represented by area 8, 9, 15 and 16. How about Indonesian waterways? It is fact that Indonesian waterways in the GWS map is only circled by area $61,62,40,52,63,71,79,78,77$ and 70. These area do not cover entire Indonesian waterways, that consists of outer area and inner area. These may give the unique wave characteristics and it is necessary to define wave data area based on actual the wave characteristic of Indonesian waterways.

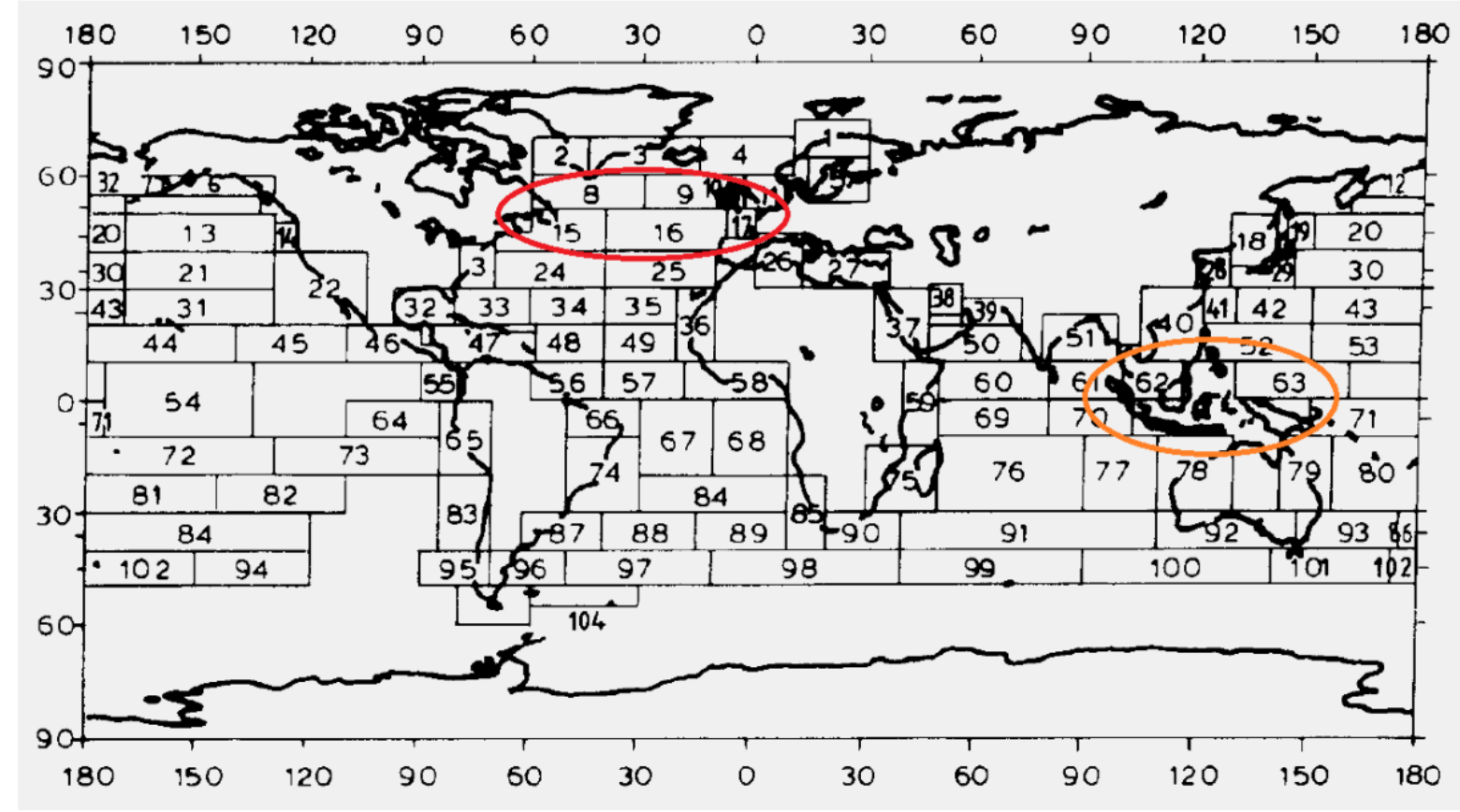

Figure 1: Global wave statistics map [4].

The reports to support the Indonesian wave enviromental data were conducted by [5], [6] and [7]. As example, [5] makes study regarding several area of Indonesian waters, that are north Natuna sea, south Natuna sea, west Java sea, west Celebes sea, west Banda sea, east Banda sea, south Sunda strait, and south Lombok strait. Thus, the concept was updated and modified by taking into account the uncovered area of Indonesian waterways by using balanced criteria of spatial size. Therefore, the last concept still has a limited accuracy, when an area covers outer part and inner part of Indonesian waterways (eg. an area covers the some part of Malacca strait and a part of west coast of Sumatera Island and Indian Ocean). In the following report, [8] proposed new definition of area based on $2^{\circ} \mathrm{x}$ 
$2^{\circ}$ spatial, and special finite area based on specific geographical location. This proposal is shown at Figure 2 and the sampling area is presented in Error! Reference source not found.

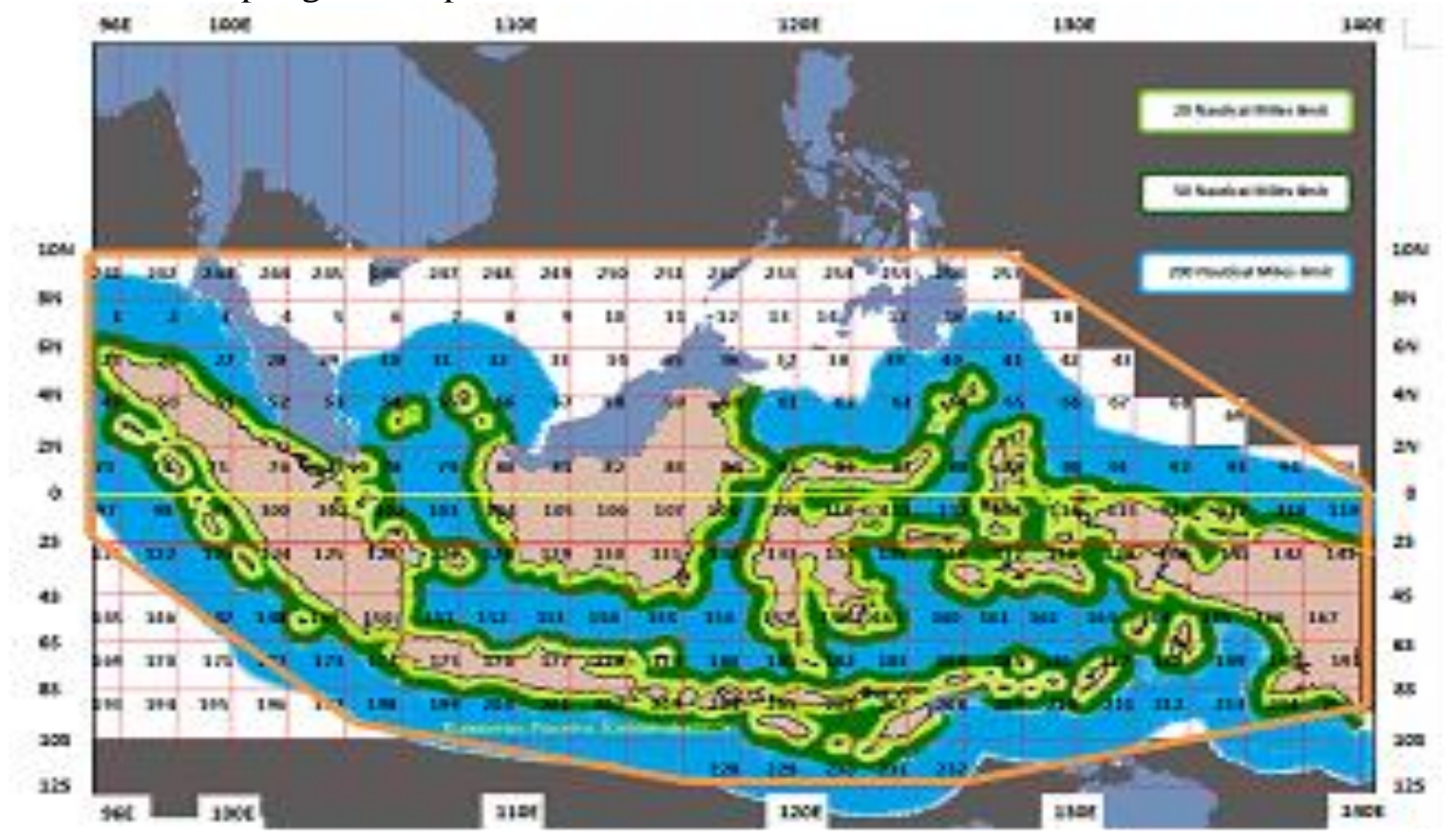

Figure 2: Indonesian wave scatter map [8].

\subsection{Hindcast Data}

This paper is based on hind-cast of the Indonesian waterways wave data. The European centre for medium weather forecast (ECMWF) was chosen to provide the hindcast data. Data was collected from the inner area of $90^{\circ} \mathrm{E} \sim 142^{\circ} \mathrm{E}$ and $15^{\circ} \mathrm{N} \sim 15^{\circ} \mathrm{S}$. The accuracy of data depends to the spatial of grid point, that is $0.25^{\circ}$. In other to simplify and reduce the time consumed, $0.75^{\circ}$ and $1.0^{\circ}$ accuracy are used in common work to produce this report, however, the original grid lattice accuracy is established in some condition. The data was collected from 4 times periodical per days (06.00am, 12.00am, $18.00 \mathrm{pm}$, and $24.00 \mathrm{pm}$ ) from period 1979 to 2014 .

Table 1: The areas of Indonesian waterways [8]. Sampling areas are presented.

\begin{tabular}{llll}
\hline No. & Area & Longitude range & Latitude range \\
\hline$\ldots$ & & $100^{\circ} \mathrm{E} \sim 102^{\circ} \mathrm{E}$ & $8^{\circ} \mathrm{N} \sim 6^{\circ} \mathrm{N}$ \\
4 & 4 & $102^{\circ} \mathrm{E} \sim 104^{\circ} \mathrm{E}$ & $8^{\circ} \mathrm{N} \sim 6^{\circ} \mathrm{N}$ \\
5 & 5 & $96^{\circ} \mathrm{E} \sim 97^{\circ} \mathrm{E}$ & $2^{\circ} \mathrm{N} \sim 1^{\circ} \mathrm{N}$ \\
$\ldots$ & & $97^{\circ} \mathrm{E} \sim 98^{\circ} \mathrm{E}$ & $2^{\circ} \mathrm{N} \sim 1^{\circ} \mathrm{N}$ \\
75 & $74 \mathrm{NW}$ & & \\
76 & $74 \mathrm{NE}$ & $98^{\circ} \mathrm{E} \sim 99^{\circ} \mathrm{E}$ & $0^{\circ} \mathrm{N} \sim 1^{\circ} \mathrm{S}$ \\
$\ldots$ & & $99^{\circ} \mathrm{E} \sim 100^{\circ} \mathrm{E}$ & $0^{\circ} \mathrm{N} \sim 1^{\circ} \mathrm{S}$ \\
107 & $99 \mathrm{NW}$ & $98^{\circ} \mathrm{E} \sim 99^{\circ} \mathrm{E}$ & $1^{\circ} \mathrm{S} \sim 2^{\circ} \mathrm{S}$ \\
108 & $99 \mathrm{NE}$ & $9^{\circ} \mathrm{E} \sim 100^{\circ} \mathrm{E}$ & $1^{\circ} \mathrm{S} \sim 2^{\circ} \mathrm{S}$ \\
109 & $99 \mathrm{SW}$ & & \\
110 & $99 \mathrm{SE}$ & $140^{\circ} \mathrm{E} \sim 142^{\circ} \mathrm{E}$ & $10^{\circ} \mathrm{N} \sim 8^{\circ} \mathrm{N}$ \\
\hline.. & &
\end{tabular}




\section{Wave Characteristics}

In this section, the hindcast data will be examined and compared with that of North Atlantic Ocean.

\subsection{Analysis Method}

The time history of hindcast data is primary wave enviromental data that is used in this work. The data consists of significant wave height (HW), mean period (TW), wave direction $(\theta \mathrm{W})$.

The maximum HW during 30 years data collecting period are analzed and compared between North Atlantic Ocean and Indonesian waterways. Data location are selected based on points that is in 20 nautical miles, 50 nautical miles and 200 nautical miles from shore (see Figure 3. The total point locations for both of two waters area (North Atlantic ocean and Indonesian waterways) are 750 points that provides HW from different distance from shore.

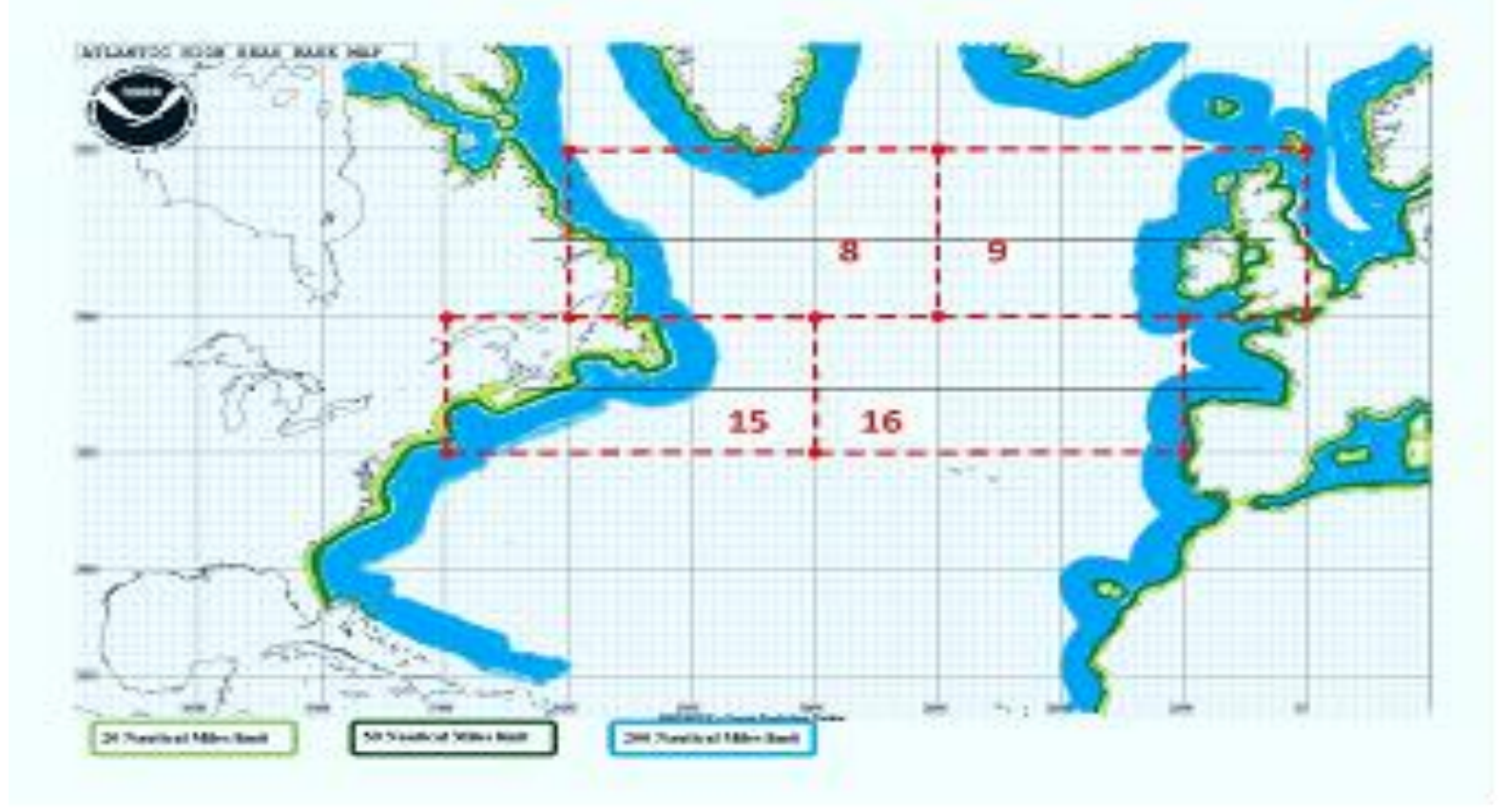

Figure 3: The mapping of North Atlantic Ocean to provide data.

43680 points of location are used to provide the wave scatter data for area of Indonesian waterways (see Table 1 and Figure 1). Figure 4 shows the points locations that provide the wave enviromental data.

In the assembling process of wave scatter data, the maximum $\mathrm{Hw}$ for each point locations is compiled and the changing nature of time history of $\mathrm{Hw}_{\mathrm{w}}$ (see Figure 5) is analyzed to identify the storm condition. The storm at Indonesian waterways is identified based on the procedure and storm definition that is described by [9]. Figure 6 shows the typical storm that could be identified from $\mathrm{Hw}$ time histories. The storm is profiled from crescendo de crescendo of individual wave height based on maximum $\mathrm{Hw}$ for each storm class and storm duration. 


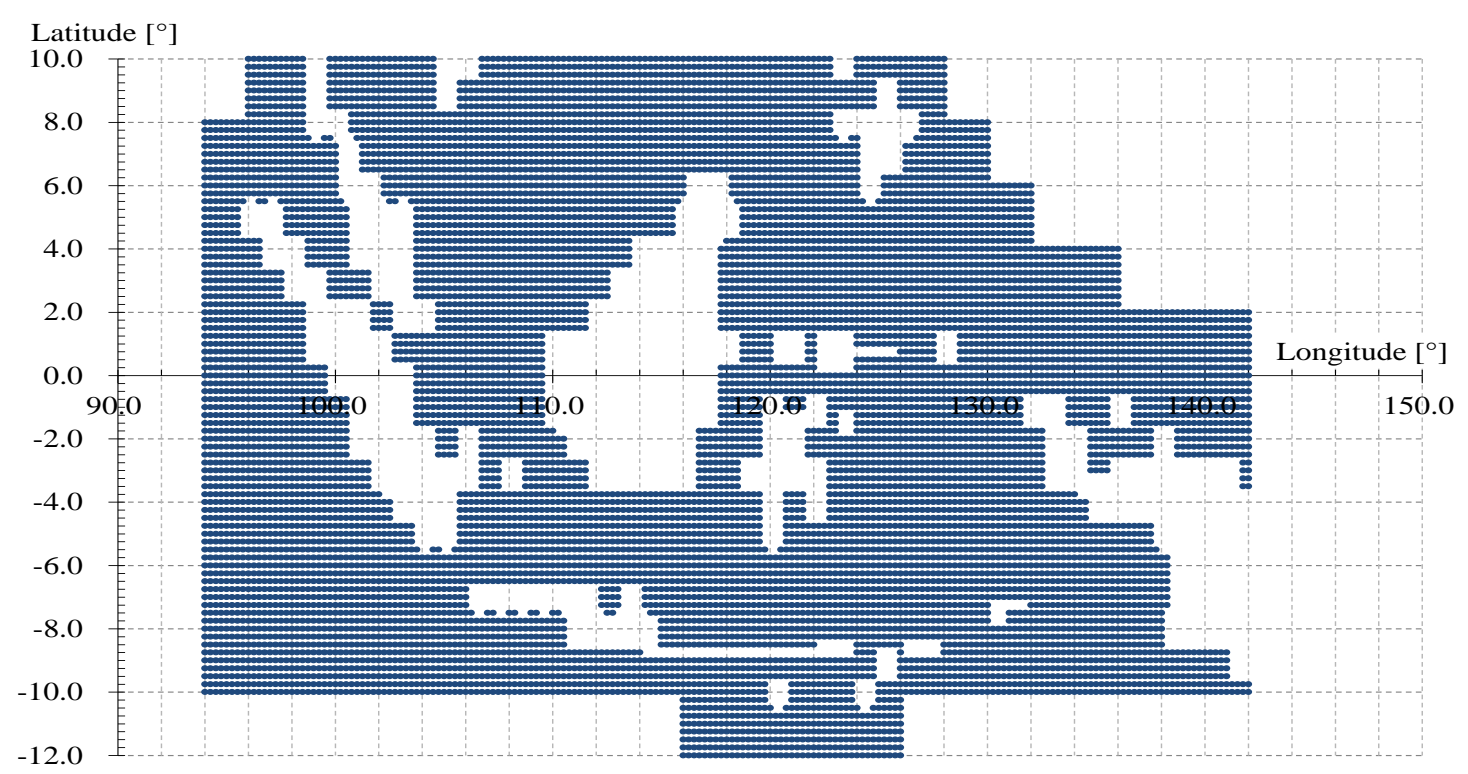

Figure 4: Locations to provide the wave environmental data.

The example of $\mathrm{H}_{\mathrm{W}}$ data history

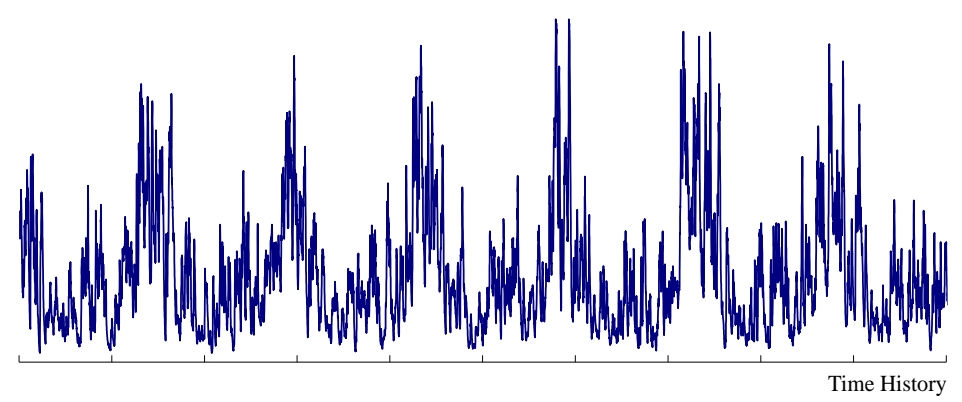

Figure 5: The example of Hw time history

\subsection{Statistical Characteristic}

Identification of statistical characteristics is conducted to all chosen points (Figure 4). The statistical characteristics shows that the minimum of $\mathrm{Hw}_{w}$ is 0.68 meter, maximum of $\mathrm{Hw}$ is 7.23 meter and mean of $\mathrm{Hw}_{\mathrm{w}}$ is 3.47 meter. The $\mathrm{Hw}_{\mathrm{w}}$ distribution ranges with standard deviation of 1.18 meter. The histogram of $\mathrm{Hw}_{\mathrm{w}}$ distribution is depicted in Figure 7 This figure presents three ranges of $\mathrm{Hw}$ zone as shown on Table 2. Here, the range of zone 2 has dominant population ( $51.1 \%$ ), zone 3 is $47.25 \%$ and zone 1 is $1.61 \%$. It could be concluded that, wave enviromental condition of Indonesian waterways is not severe since the dominan population of $\mathrm{Hw}_{\mathrm{w}}$ is less than 3.5 meter and it is less than mean of $\mathrm{Hw}_{\mathrm{w}}$ [3.47 meter]. 


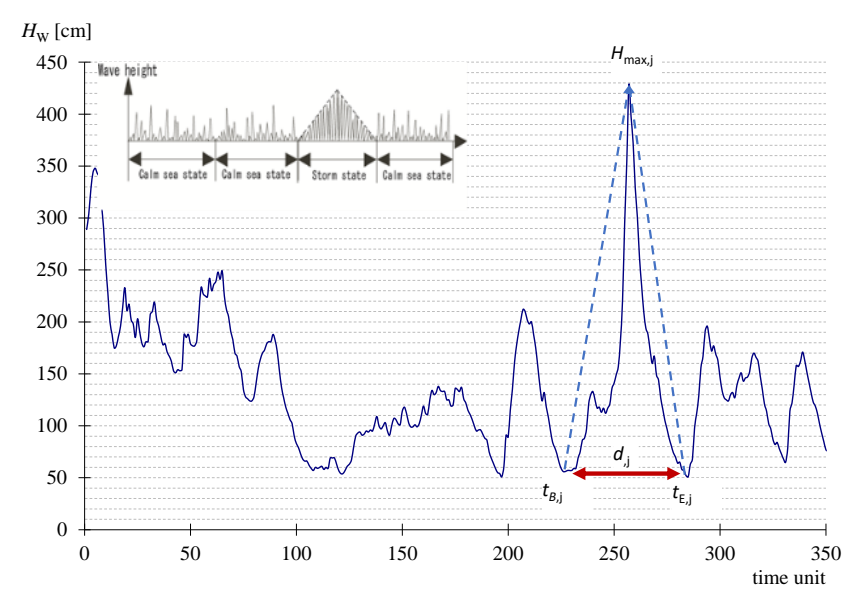

Figure 6: Typical storm definition [9] based on equivalent triangular storm.

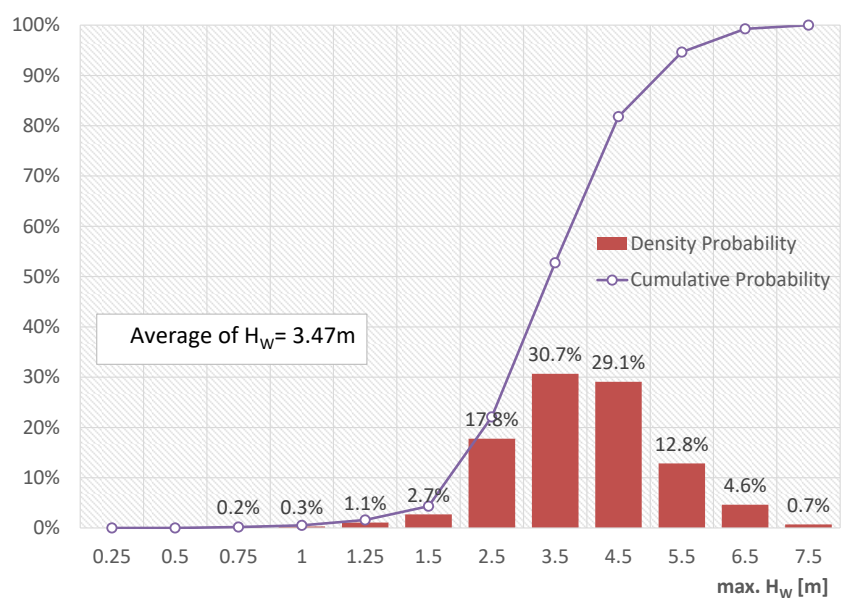

Figure 7: The histogram of $\mathrm{Hw}$ distribution at points locations of Indonesian waterways (Figure 4).

Table 2: Hw distribution of Indonesian waterways

\begin{tabular}{|l|l|}
\hline Zone & Description \\
\hline 1 & $\mathrm{H}_{\mathrm{W}}<1.5$ meter \\
\hline 2 & 1.5 meter $\leq \mathrm{H}_{\mathrm{W}} \leq 3.5$ meter \\
\hline 3 & $\mathrm{H}_{\mathrm{W}}>3.5$ meter \\
\hline
\end{tabular}

Thus, the rough wave is identified based on storm identification procedure. The storm is identified for each HW time history,and storm number that is identified at Indonesian waterways is about 69708 storms. The minimum storm class is 2 meter and maximum storm class is 9 meter. Figure 8 shows the occurence frequency of storm based on its duration identified at Indonesian waterways. The statistical characteristics of storm duration is presented in Error! Reference source not found.The storm will have duration in average between 2.00 days to 2.86 days in Indonesia waterways. In order to support design process, storm duration and storm class, is analyzed by using its probability distribution. Figure 9 and Figure 10 show probability distribution of storm duration and that of storm class. It is found that storm duration could be estimated by using the linear interpolation of lognormal of exceedance probability (see Figure 9). The fact is supported with the report of [9], when they examined and compared the storm identified at tropical and sub-tropical area. Indonesian waterways 
is as a part of tropical area and North Atlantic Ocean is as a part on sub-tropical area. [10] reported that the storm duration of North Atlantic area could be estimated by using normal distribution. Furthermore, Figure 10 shows the regressed of storm class by using normal distribution and its comparison with that of probability distribution of storm class. The fitness of the result shows good agreement.

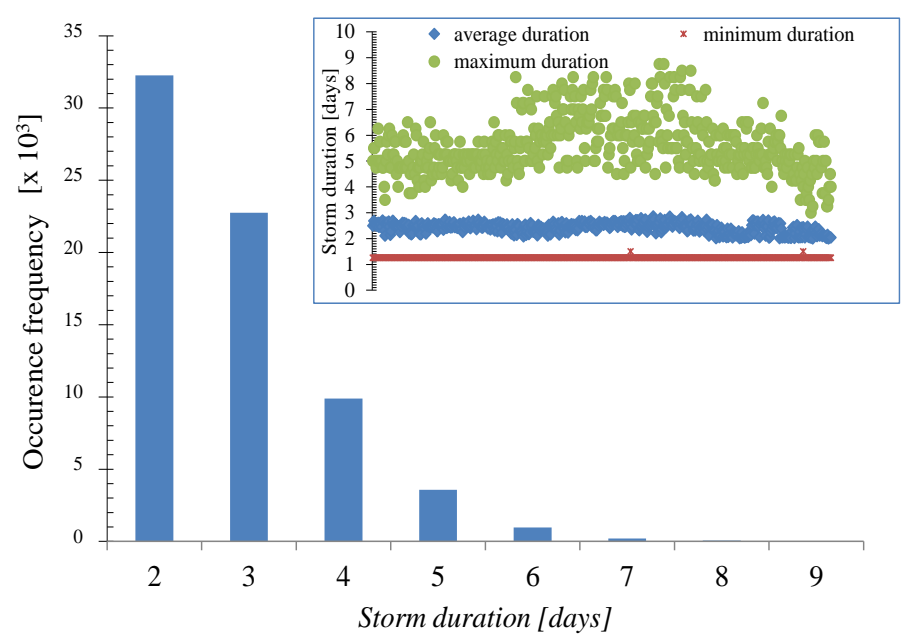

Figure 8: The frequency of storm duration that is identified at Indonesian waterways.

Table 3: The statistical characteristics of storm duration

\begin{tabular}{|l|l|l|}
\hline & Min.duration & Max.duration \\
\hline Maximum storm duration & 3.00 days & 8.75 days \\
\hline Average storm duration & 2.00 days & 2.86 days \\
\hline Minimum storm duration & 1.25 days & 1.50 days \\
\hline
\end{tabular}

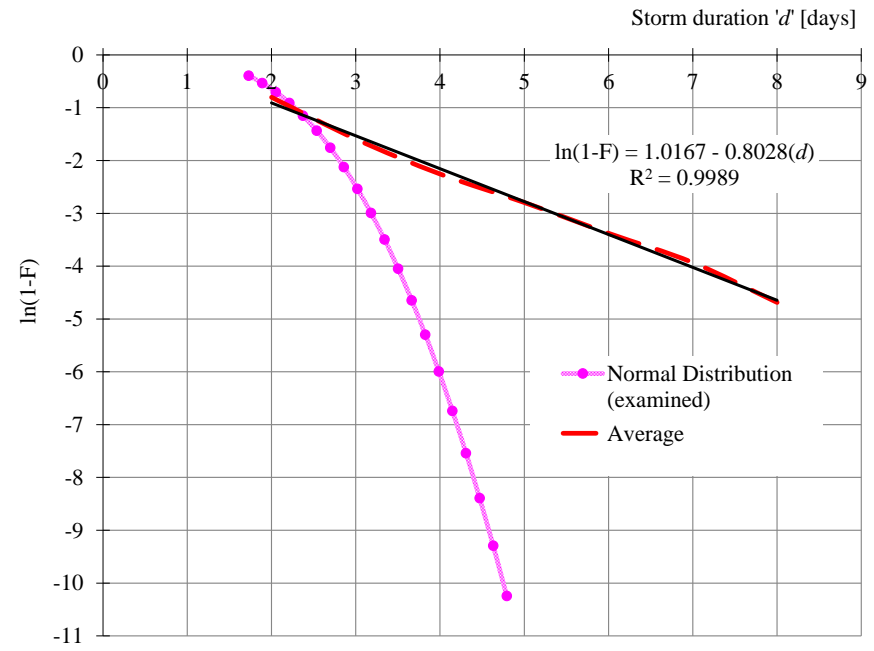

Figure 9: The probability distribution of storm duration and its proposed regression method.

The final aim of the previous process is to generate wave scatter data for all area of Indonesian waterways (Figure 2). Once the wave scatter data is assembled, the statistical characteristic of scatter data could be examined. [10] shown that wave scatter data of area that is located on North Pacific 
Ocean and North Atlantic ocean and asembled from hindcast data, could follow the Weibull distribution to estimate their long-term distribution.

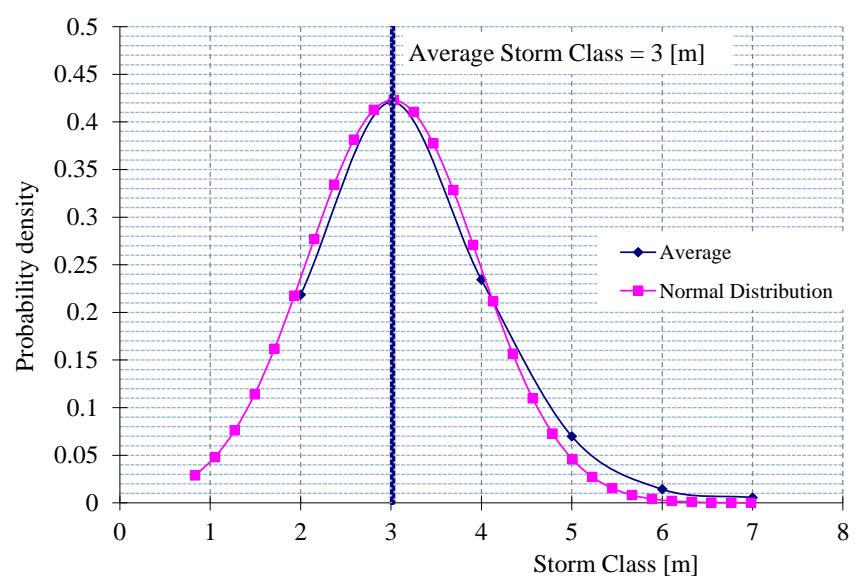

Figure 10: The probability distribution of storm class and its proposed regression method.

Based on assembled wave scatter data, the maximum HW of all areas is foundand it is presented in Figure 11 and its histogram distribution can be seen in Figure 12. The maximum of HW maximum is 7.04 meter, minimum of $\mathrm{HW}$ maximum is 0.92 meter and its average is 3.726 meter.

In general, cumulative probability density $\mathrm{F}(\mathrm{HW})$ of Weibull distribution and its probability density could be formulated as equation (1)[11].

$$
\mathrm{F}(\mathrm{Hw})=1-\exp \left\{-1 \cdot\left(\mathrm{Hw}_{\mathrm{w}} \cdot \lambda^{-1}\right)^{\mathrm{k}}\right\}
$$

where, $\mathrm{k}$ and $\lambda$ are Weibull's shape and Weibull's scale parameters.

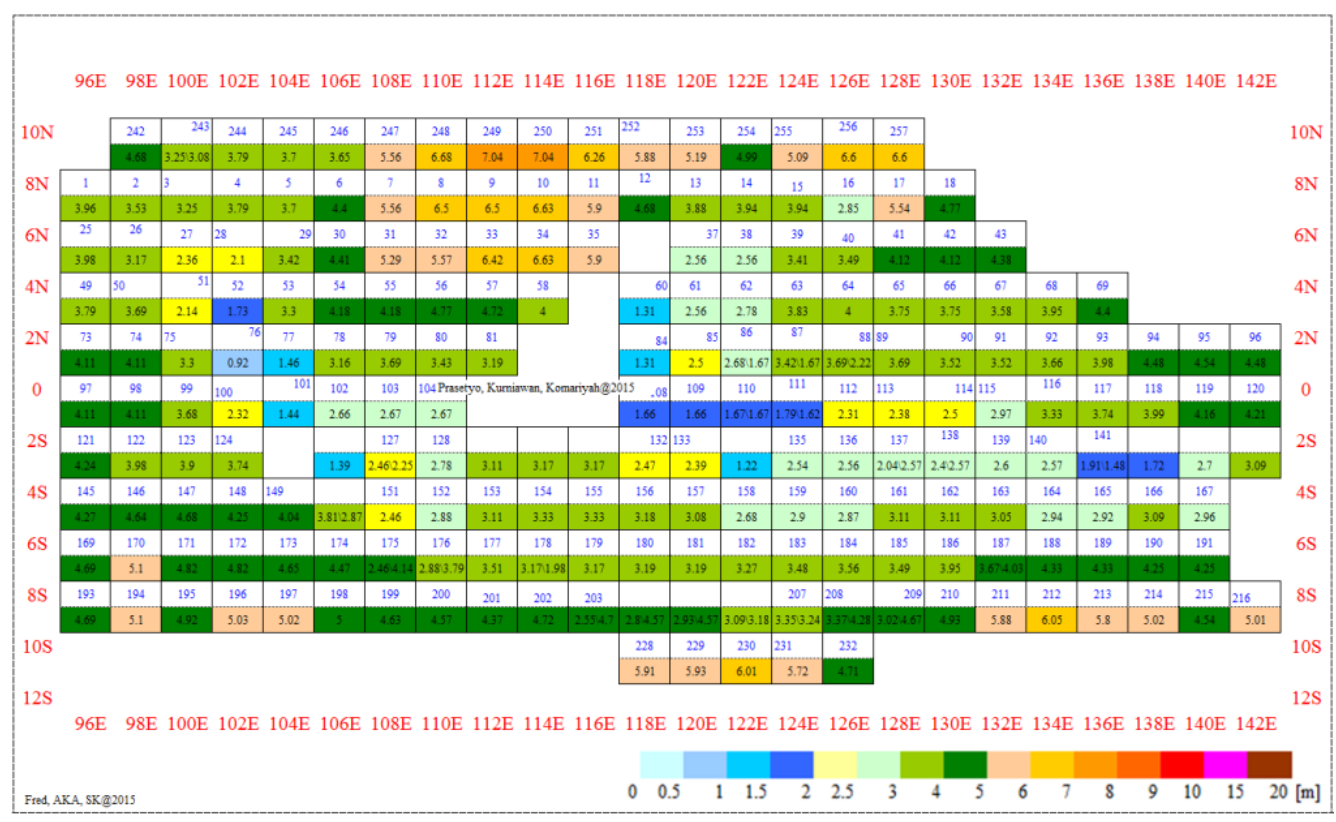

Figure 11: Maximum Hw of areas of Indonesian waterways. Areas are defined as Figure 2. 


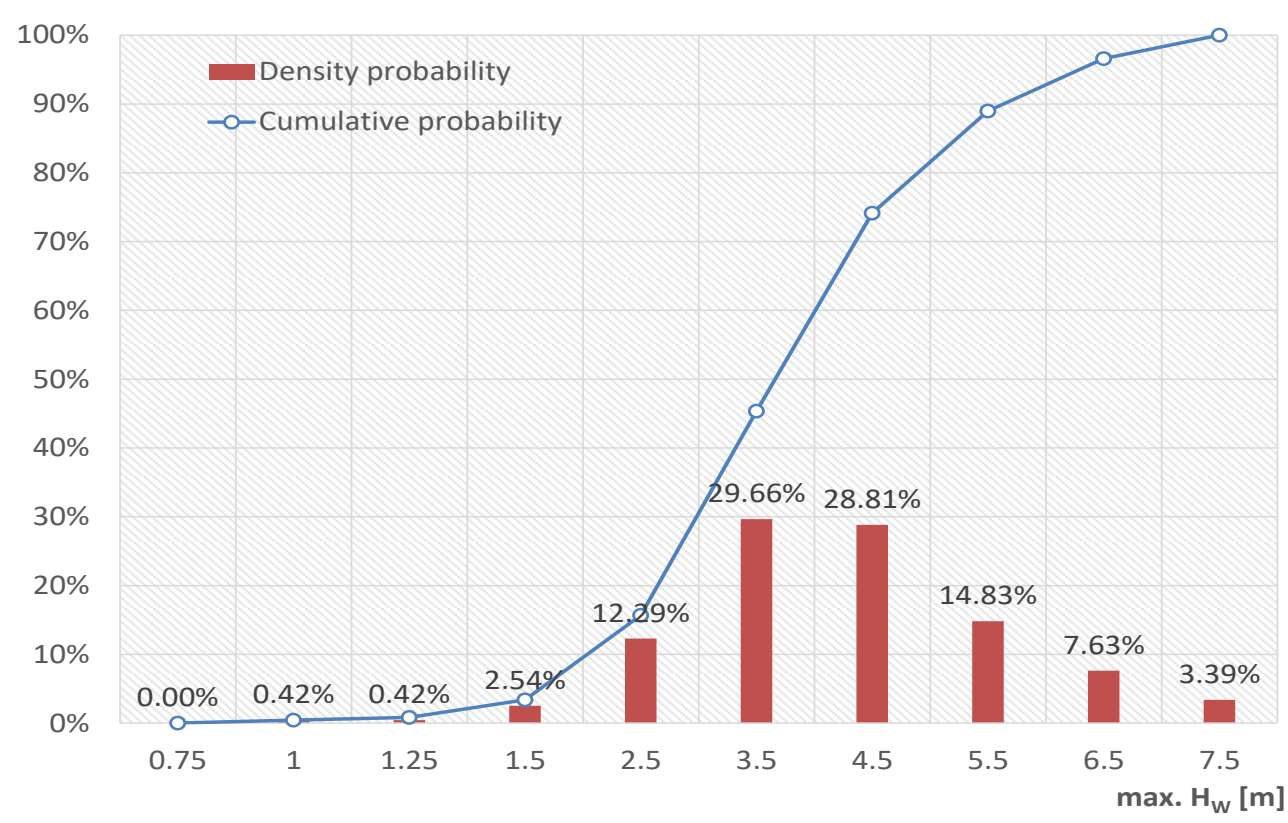

Figure 12: Histogram of maximum $\mathrm{Hw}$ at all areas of Indonesian waterways. Areas are defined as Figure 2.

Figure 13 shows the Weibull plot of average Indonesian waterways wave scatter data. The relation between normal logarithme of HW and that of double normal logarithme of the function of HW exceedance probability could be presented by linear straight line in this figure. The Weibull's parameter ( $\mathrm{k}$ and $\lambda$ ) could be determined by using least square method.

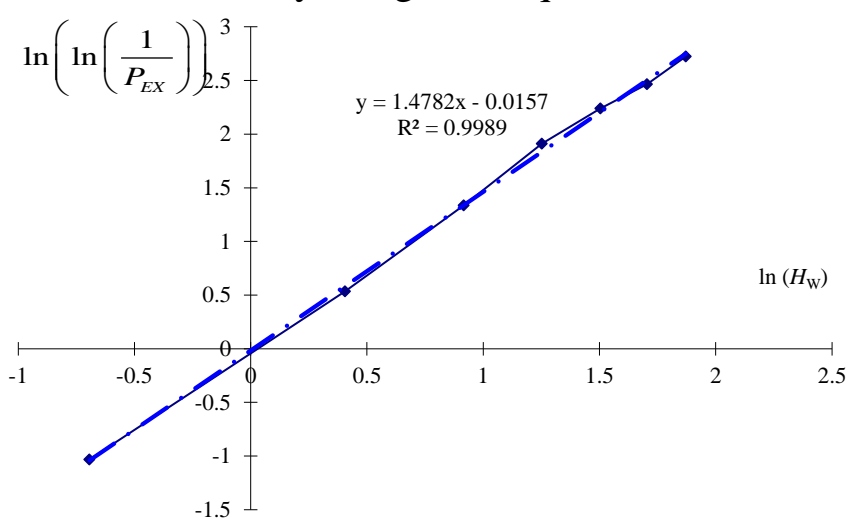

Figure 13: Weibull plot of average Indonesian waterways wave scatter data.

In order to clarify, area $32\left(108^{\circ} \mathrm{E} \sim 110^{\circ} \mathrm{E} ; 6^{\circ} \mathrm{N} \sim 4^{\circ} \mathrm{N}\right)$ is chosen for the sampling assessment. Once the Weibull's parameter was identified, the regressed estimation could be compared with that of the original ones. Figure 14 shows the regressed of Weibull distribution at area 32. The original data is also plotted as reference. It presents a good agreement between Weibull's regressed distribution and the original one. It could be concluded that the long term distribution of wave scatter data of areas on Indonesian waterways could be estimated by using Weibull distribution as well as that of North Atlantic ocean. Thus, the wave scatter data of Indonesian waterwas along all areas could be generated. The sample of wave scatter data is presented with Figure 15 and the area is area 32. 


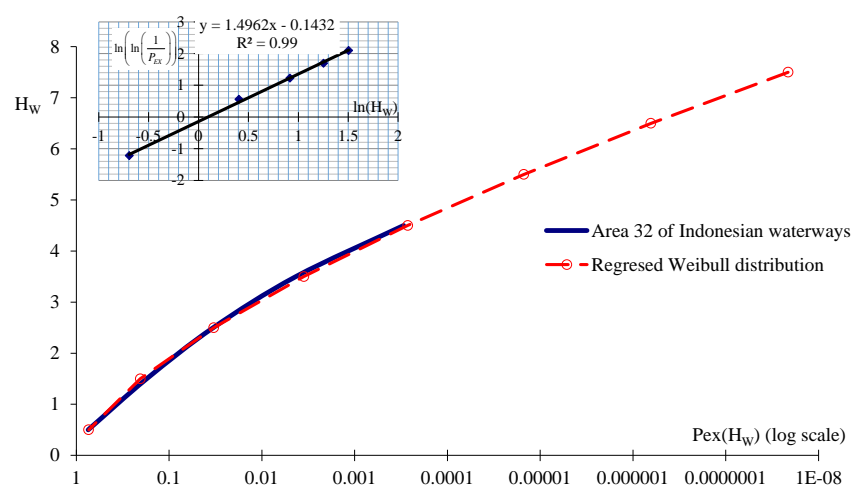

Figure 14: Comparison of regressed based on Weibull distribution and its original data. Area 32 is presented.

Indonesian Wave Scatter map, Area:32

\begin{tabular}{|r|r|r|r|r|r|r|r|r|r|r|r|r|r|r|}
\hline $\mathbf{H}_{\mathbf{W}} / \mathbf{T}_{\mathbf{W}}$ & $\mathbf{2}$ & $\mathbf{3}$ & $\mathbf{4}$ & $\mathbf{5}$ & $\mathbf{6}$ & $\mathbf{7}$ & $\mathbf{8}$ & $\mathbf{9}$ & $\mathbf{1 0}$ & $\mathbf{1 1}$ & $\mathbf{1 2}$ & $\mathbf{1 3}$ & Sum \\
\hline $\mathbf{7 . 5}$ & 0.00 & 0.00 & 0.00 & 0.00 & 0.00 & 0.00 & 0.00 & 0.00 & 0.00 & 0.00 & 0.00 & 0.00 & 0.00 \\
\hline $\mathbf{6 . 5}$ & 0.00 & 0.00 & 0.00 & 0.00 & 0.00 & 0.00 & 0.00 & 0.00 & 0.00 & 0.00 & 0.00 & 0.00 & 0.00 \\
\hline $\mathbf{5 . 5}$ & 0.00 & 0.00 & 0.00 & 0.00 & 0.00 & 0.00 & 0.00 & 0.00 & 19.77 & 9.88 & 0.99 & 0.00 & 30.64 \\
\hline $\mathbf{4 . 5}$ & 0.00 & 0.00 & 0.00 & 0.00 & 0.00 & 0.00 & 0.00 & 155.16 & 218.41 & 23.72 & 2.96 & 0.00 & 400.25 \\
\hline $\mathbf{3 . 5}$ & 0.00 & 0.00 & 0.00 & 0.00 & 0.00 & 6.92 & 838.05 & 1551.58 & 402.23 & 99.82 & 12.85 & 0.00 & 2911.44 \\
\hline $\mathbf{2 . 5}$ & 0.00 & 0.00 & 0.00 & 1.98 & 1041.64 & 4266.36 & 5318.87 & 2351.09 & 899.33 & 173.94 & 23.72 & 0.99 & 14077.90 \\
\hline $\mathbf{1 . 5}$ & 0.00 & 2.96 & 5126.15 & 17492.37 & 15255.91 & 11046.87 & 5658.83 & 2116.87 & 336.01 & 32.61 & 1.98 & 0.00 & 57070.57 \\
\hline $\mathbf{0 . 5}$ & 1.98 & 1009.02 & 9043.65 & 9568.42 & 4627.08 & 1053.50 & 182.83 & 17.79 & 4.94 & 0.00 & 0.00 & 0.00 & 25509.21 \\
\hline Total = & 1.98 & 1011.99 & 14169.80 & 27062.76 & 20924.62 & 16373.64 & 11998.58 & 6192.50 & 1880.68 & 339.96 & 42.50 & 0.99 & 100000 \\
\hline
\end{tabular}

Figure 15: Wave scatter data of Indonesian waterways. Area 32 is chosen as a sample.

\subsection{Comparative Analysis between North Atlantic Ocean and Indonesian Waterways}

In relation with the previous analysis, the chosen points that are located in 20 nautical miles, 50 nautical miles and 200 nautical miles from shore are compared with that of North Atlantic ocean. Figure 16 shows the histogram that compare $\mathrm{Hw}$ at specific location from shore. This graphic presents that the average $\mathrm{Hw}$ of North Atlantic ocean is higher than that of Indonesian waterways for the case of 200 nautical miles. This condition is also applied to the minimum and maximum $\mathrm{Hw}$ for all cases of distance from shore. In general, this means that the ratio of $\mathrm{Hw}$ in North Atlantic ocean is $400 \%$ than that Indonesian waterways. However, some condition shows that the ratio between two different oceans is up to $700 \%$. The straight line that connect the minimum - average - maximum $\mathrm{Hw}$ for cases 200 nautical miles is presented. The slope of straight line shows that North Atlantic Ocean has a tendency about 3 times than Indonesian waterways.

After wave scatter data was assembled, the long-term and short term probability distribution could be identified by using those wave scatter data and chosen statistical distribution. The long-term probability distribution of Indonesian waterways wave scatter data could be assumed by using Weibull distribution as discussed in above paragraph. In general, ships is designed for 20 years life. It is common to use wave enviromental return period of 20 years (minimum) with 6 second mean period and its coressponding to $10^{-8}$ exceedance probability per cycle [12]. Figure 17 shows the $\mathrm{Hw}$ characteristics which coresponds to $10^{-8}$ exceedance probability for all areas of Indonesian waterways. The maximum, minimum, average of $\mathrm{Hw}$ corresponding to $10^{-8}$ is shown in Figure 18 . The wave characteristic of North Atlantic ocean and Indonesian waterways are presented. It is shown 
that $\mathrm{Hw}\left(10^{-8}\right)$ of North Atlantic Ocean is higher than that of Indonesian waterways. The maximum ratio is about $517 \%$.

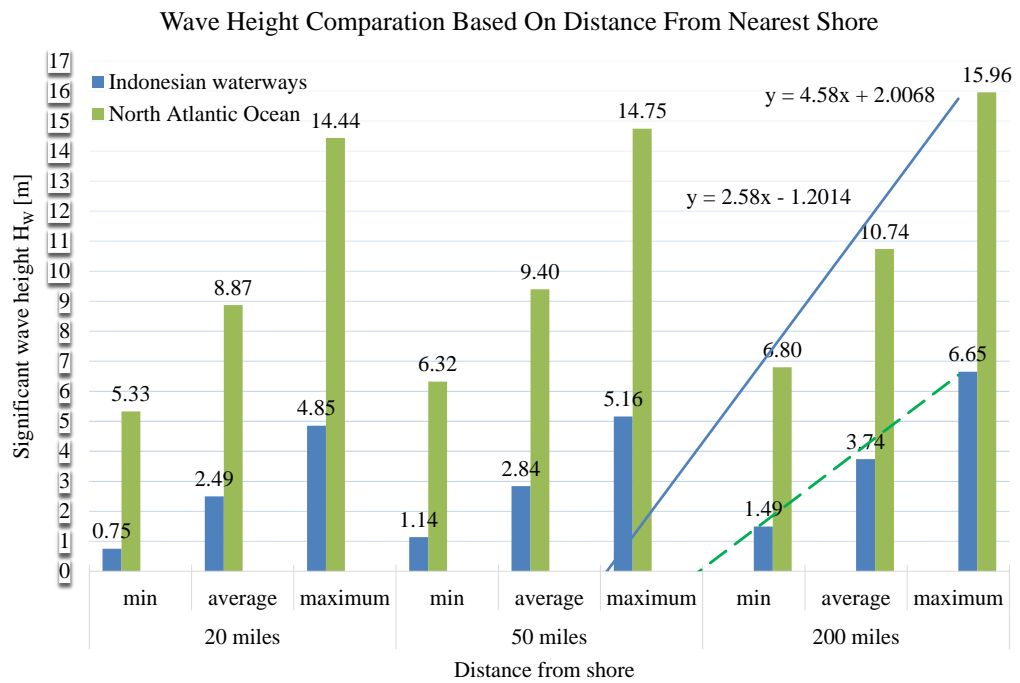

Figure 16: Comparison of $\mathrm{Hw}_{\mathrm{w}}$ between North Atlantic Ocean and Indonesian waterways. The point is located is several distance from shore, 20 nautical miles, 50 nautical miles and 200 nautical miles.

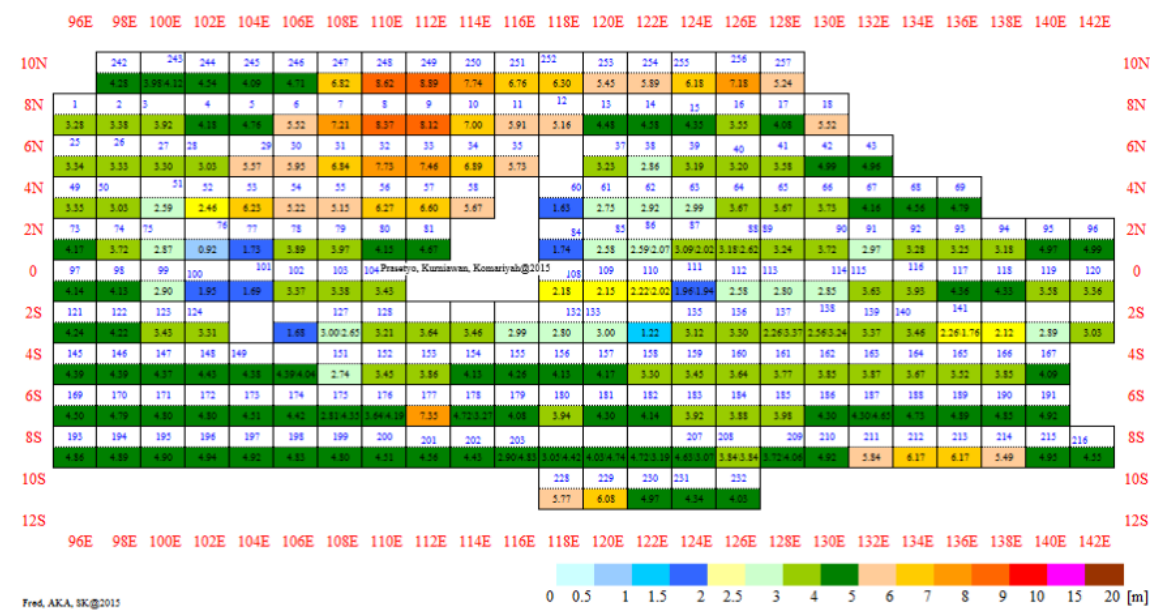

Figure 17: $10^{-8}$ exceedance probability of $\mathrm{Hw}_{\mathrm{w}}$ for all areas of Indonesia waterways.

\section{Conclusions}

The progress work to identify the wave characteristic of Indonesian waterways is reported. The wave characteristic is based on the hindcast data, that is provided along Indonesian waterways. The analysis of wave characteristics is started by defining the wave scatter map, assembling wave scatter data, and finally identifying the wave condition that is corresponded to the $10^{-8}$ exceedance probability.

Furthermore, this work also identify the rogue wave condition along Indonesian waterways based on storm profile (storm duration and storm class). The storm duration could be estimated by using linear interpolation of lognormal of exceedance probability and storm class could be estimated by using normal distribution. The wave scatter data of Indonesian waterways has been asembled and its long-term distribution could be identified. The long-term distribution of HW could be estimated by using Weibull distribution. Finally, it is found that the $10^{-8}$ of HW along North Atlantic Ocean is 
about $517 \%$ higher than that of Indonesian waterways. This difference could give substantial effect to the ship design process.

The future work will be focus on the study and discussing to the respon of ship structure, or ship system and equipment by considering the above results.

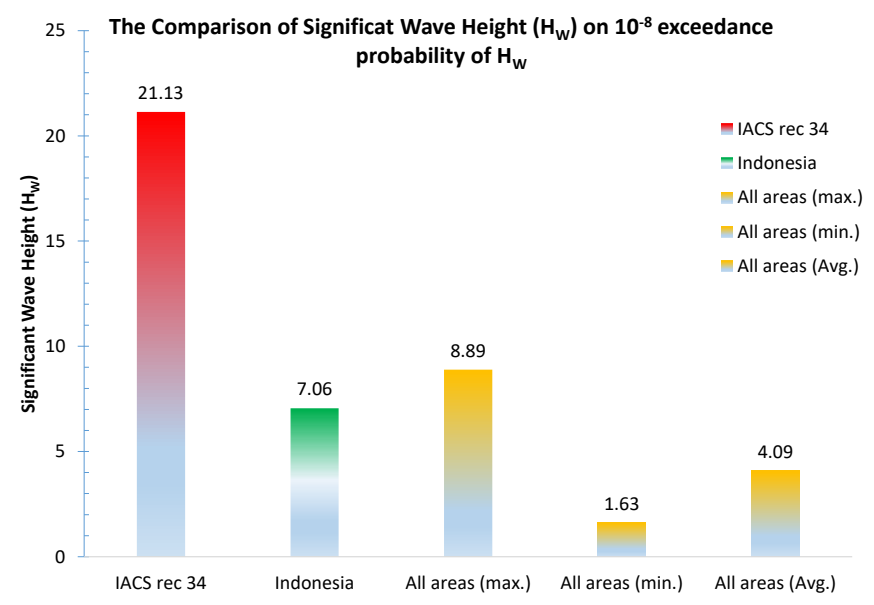

Figure 18: Comparison of Hw corresponding to $10^{-8}$. The wave characteristic of North Atlantic Ocean and Indonesian waterways was presented.

\section{Acknowledgements}

Met-ocean data from ECMWF is owned by the European Centre for Medium-Range Weather Forecasts (ECMWF) and accessed and downloaded from http://dataportal.ecmwf.int/data/d/interim_full_daily/.

This study is part of research activities of the "Wave-structure-material" Research and Development Division conducted by Fredhi Agung Prasetyo, Mohammad Arif Kurniawan and Siti Komariyah. The authors would like to thank you for all assistance given in this research activity

\section{References}

[1] IACS, "Common structural rules for Bulk Carriers and Oil Tankers, IACS, 1 January 2014.

[2] IMO, "Adoption of the International goal-based ship construction standards for Bulk Carriers and Oil Tankers", IMO MSC.287(87), 20May 2010.

[3] N Hogben, N M Dacunha, F Olliver, "Global wave statistics”, British Maritime Technology, 1985.

[4] IACS, “Standar wave data”, IACS Rec. No.34, 2001.

[5] Y Sakuno, M Hamamoto, B H Iskandar, J P Panjaitan, O Yaacob, "Wave data collection and analysis in Indonesian domestic seas, Final report for collection of wave data and safety of ships operating in Indonesian Domestics Seas ", The JSPS-DGHE program in Marine Transportation engineering group of investigation on Safety Management in Indonesia, 2006.

[6] O Yacoob, "Development of a Malaysian ocean wave database and models for engineering purposes", Report of Research vote No. 74328, Fakulti Kejuruan Mekanikal, Universiti Teknologi Malaysia, 2006.

[7] M A Kurniawan, A Sulistyono, P E Panunggal, "Spectrum parametric modification for analyzed long-short-term wave in Indonesian waterways by using Fourier transformation", proceeding of Asian-Pacific Technical Exchange and Advisory Meeting on Marine Structures (TEAM), (2013),141-148.

[8] M A Kurniawan, F A Prasetyo, S Komariyah, "Study on wave scatter mapping of Indonesia waterways based on hind-cast data”, proceeding of Asian-Pacific Technical Exchange and Advisory Meeting (TEAM) 2014.

[9] F A Prasetyo, M A kurniawan, S Komariyah, Rudiyanto, T Herawan, " Storm model application at Indonesian tropical ocean", ICCSA 2017, part IV, LNCS 10407, pp.732-745, 2017.

[10]F A Prasetyo, "Study on advanced storm model for fatigue assessment of ship structural member", Doctoral dissertation, Osaka University Suita Japan, 2013.

[11]M Evans, N Hastings, B Peacock, "Statistical distributions, John Wiley \& sons, Inc., 2000. 